\title{
HELIUM-COOLED REFRACTORY ALLOYS FIRST WALL AND BLANKET EVALUATION
}

\author{
by
}

C.P.C. WONG, R.E. NYGREN, ${ }^{\dagger}$ C.B. BAXI, P. FOGARTY, $\ddagger$ N. GHONIEM, $\Delta$ H. KHATER, $\diamond$ K. MCCARTHY,§ B. MERRILL,§ B. NELSON, ‡E.E. REIS, S. SHARAFAT, $\triangle$ R. SCHLEICHER, D.K. SZE, "M. ULRICKSON, ${ }^{\dagger}$ S. WILLMS, \& M. YOUSSEF, $\Delta$ S. ZINKEL, $\triangle$ and the APEX TEAM

This is a preprint of a paper to be presented at the 5th International Symposium on Fusion Nuclear Technology, September 19-24, 1999, in Roma, Italy, and to be published in Fusion Engineering and Design.

$$
\begin{gathered}
\text { †Sandia National Laboratories } \\
\text { ₹Oak Ridge National Laboratory, Oak Ridge, Tennessee } \\
\Delta \text { University of California, Los Angeles, California } \\
\text { @university of Wisconsin, Madison, Wisconsin } \\
\text { §Lockheed Martin Idaho Technologies Co. } \\
\text { \#Argonne National Laboratory, Argonne, Illinois } \\
\text { \&Los Alamos National Laboratory, New Mexico }
\end{gathered}
$$

\author{
Work supported by \\ the U.S. Department of Energy \\ under Contract Nos. DE-AC03-99ER54463, DE-AC04-94AL85000, \\ DE-AC05-96OR22464, W-31-109-ENG-38, W-7405-ENG-36, and \\ Grant No. DE-FG03-86ER54299
}

PROCESSEO ROOM BEST AVALABLE CGPY

\section{GA PROJECT 30033 \\ AUGUST 1999}




\section{DISCLAIMER}

This report was prepared as an account of work sponsored by an agency of the United States Government. Neither the United States Government nor any agency thereof, nor any of their employees, make any warranty, express or implied, or assumes any legal liability or responsibility for the accuracy, completeness, or usefulness of any information, apparatus, product, or process disclosed, or represents that its use would not infringe privately owned rights. Reference herein to any specific commercial product, process, or service by trade name, trademark, manufacturer, or otherwise does not necessarily constitute or imply its endorsement, recommendation, or favoring by the United States Government or any agency thereof. The views and opinions of authors expressed herein do not necessarily state or reflect those of the United States Government or any agency thereof. 


\section{DISCLAIMER}

Portions of this document may be illegible in electronic image products. Images are produced from the best available original document. 


\begin{abstract}
Under the APEX program the He-cooled system design task is to evaluate and recommend high power density refractory alloy first wall and blanket designs and to recommend and initiate tests to address critical issues. We completed the preliminary design of a helium-cooled, W-5Re alloy, lithium breeder design and the results are reported in this paper. Many areas of the design were assessed, including material selection, helium impurity control, and mechanical, nuclear and thermal hydraulics design, and waste disposal, tritium and safety design. System study results show that at a closed cycle gas turbine (CCGT) gross thermal efficiency of $57.5 \%$, a superconducting coil tokamak reactor, with an aspect ratio of 4 , and an output power of $2 \mathrm{GWe}$, can be projected to have a cost of electricity at $54.6 \mathrm{mill} / \mathrm{kWh}$. Critical issues were identified and we plan to continue the design on some of the critical issues during the next phase of the APEX design study.
\end{abstract}




\section{INTRODUCTION}

Under the APEX program [1] the goal for the He-cooled system design task is to evaluate and recommend robust high power density refractory alloy, He-cooled first, wall and blanket (FW/blanket) design options; and to recommend and initiate tests to address critical issues. Because of the projected high allowable operating temperature of the refractory alloy, it has the potential of leading to a high thermal efficiency FW/blanket design. We initiated our task by designing for an average neutron wall loading of $7 \mathrm{MW} / \mathrm{m}^{2}$, a surface heat flux of $2 \mathrm{MW} / \mathrm{m}^{2}$, and a peaking factor of 1.4 . To meet these severe design goals, we evaluated the use of refractory alloys like Ta, Mo, W, Nb and V alloys in 1998. In 1999, with support from the APEX team, we performed the preliminary design of the W-alloy FW/blanket concept. We projected the properties of $\mathrm{W}-5 \mathrm{Re}$ alloy and evaluated the issue of material compatibility. For the first wall heat transfer design we evaluated the possible use of porous medium and swirl tube options. We performed thermal hydraulics, nuclear, activation and safety designs and analysis. High-pressure helium coolant at $12 \mathrm{MPa}$ was used and coupled to a closed-cycle gas turbine (CCGT) power conversion system (PCS). These results were then used in a system code design to evaluate the cost of electricity (COE). At the same time the critical issues related to this blanket were identified. A summary of the preliminary design of the refractory alloy helium-cooled breeder FW/blanket concept developed under the APEX program is presented in the following sections. 


\section{MATERIAL SELECTION AND COMPATIBILITY}

The APEX goal for high operating temperatures $\left(\sim 1000^{\circ} \mathrm{C}\right)$ for the structure in the high power density He-cooled concept severely limits the structural materials that can be considered. Pure tungsten or tungsten alloyed with $\sim 5 \% \operatorname{Re}$ (to improve fabricability) appear to be suitable candidates. The unirradiated mechanical properties of tungsten are strongly dependent on thermomechanical processing conditions. The best tensile and fracture toughness properties are obtained in stress-relieved material. In order to be conservative, since data are not available on the possibility of radiation-enhanced recrystallization of $\mathrm{W}$, and also to account for the presence of welds in the structure, the preliminary design is based on recrystallized mechanical properties. There are no known mechanical properties data on tungsten or tungsten alloys at irradiation and test temperatures above $\sim 800^{\circ} \mathrm{C}$. There are no known fracture toughness or Charpy impact data on tungsten irradiated at any temperature. Pronounced radiation hardening is observed in $\mathrm{W}$ and W-Re alloys irradiated at temperatures of $300-500^{\circ} \mathrm{C}$ to doses of $\sim 1-2 \mathrm{dpa}$, which produces significant embrittlement in tensile tested specimens ( $\sim 0 \%$ total elongation). Simple scaling from existing data on irradiated Mo alloys suggests that the operating temperature for W should be maintained above $\sim 800^{\circ}-900^{\circ} \mathrm{C}$ in order to avoid a significant increase in the ductile to brittle transition temperature (DBTT). The upper operating temperature limit for tungsten will be determined by thermal creep, helium embrittlement, or oxide formation issues. The thermal creep of $\mathrm{W}$ becomes significant at temperatures above $\sim 1400^{\circ} \mathrm{C}$. Helium embrittlement data are not available for tungsten; however, based on results obtained on other alloys, helium embrittlement would be expected to become significant at temperatures above $\sim 1600^{\circ} \mathrm{C}(\sim 0.5$ melting temperature, $\mathrm{T}_{\mathrm{M}}$ ). The formation of volatile oxides is another potential problem in tungsten at temperatures above $\sim 800^{\circ} \mathrm{C}$, especially during an up-to-air event. However, if the oxygen partial pressure in the helium coolant can be maintained at or below $1 \mathrm{appm}$, then the rate of corrosion is calculated to be less than $2 \mu \mathrm{m} /$ year for temperatures up to $\sim 1400^{\circ} \mathrm{C}$. In summary, the selected 
upper temperature limit for tungsten in the structure of the preliminary design He-cooled system is $1400^{\circ} \mathrm{C}$, depending on the applied stress.

\subsection{He COOLANT IMPURITY CONTROL}

Refractory metals like $\mathrm{W}, \mathrm{Mo}$, and $\mathrm{V}$ are sensitive to grain boundary oxidation and embrittlement. However, if the oxygen (including $\mathrm{H}_{2} \mathrm{O}, \mathrm{CO}_{2}, \mathrm{CO}$...etc.) partial pressure in the helium coolant can be maintained at or below 1 appm, then the rate of corrosion may be acceptable. With the use of CCGT as the PCS, without the need of using high temperature water as the secondary coolant, the ingress of oxygen impurities should be much lower than the system that uses a high temperature intermediate heat exchanger. For impurity extraction, several powder metal solid getters have been developed. Most are based on zirconium metal ( $\mathrm{ZrAl}$, ZrVFe...etc.). With these materials, hydrogen can be pumped reversibly by temperature control. These solid getters will pump active gases (oxygen, oxides, $N$, and $\mathrm{C}_{\mathrm{x}} \mathrm{H}_{\mathrm{y}}$ ) irreversibly and have been used on the tokamak experiment TFTR. In the semi-conductor industry, getters have recently achieved the control of impurities to a level lower than 1 appb. These are commercial modular units with no moving parts and are self-monitoring in design. Sandia National Laboratory is planning to install a prototype on the helium loop fusion high heat flux testing facility. 


\section{MECHANICAL DESIGN AND RELIABILITY}

The mechanical design of the helium cooled refractory blanket concept must satisfy the basic APEX design goals. These goals include minimum requirements on heat removal, shielding, tritium breeding, and availability as well as provisions for heating and diagnostic penetrations, vacuum pumping, and plasma exhaust (divertor). Several first wall and blanket system configurations were evaluated. The mechanical design is shown in Fig. 1. The helium cooled refractory alloy design includes a high temperature helium-cooled first wall and a lithium bath that is also cooled with high temperature helium. The first wall is made up of separate units, which in this case are connected to separate cooling manifolds at the back of each module. The first wall units consist of multiple parallel passages connected through an integral manifold to round inlet and outlet connections. The large modules contain the lithium in a single volume, with pure lithium in the breeding zone and a combination of lithium and steel balls in the shielding zone. The temperature is relatively uniform, although there will be some gradients, albeit transient, between the front and back structural walls. There are two inboard and three outboard modules to each of the 16 sectors arranged in the toroidal direction. The piping is routed in two circuits. The first circuit includes the first wall and part of the interior heat exchange tubing. Helium at $800^{\circ} \mathrm{C}$ enters the first wall through the supply manifold and exits into the first wall outlet manifold at $950^{\circ} \mathrm{C}$. The helium is then routed inside the lithium can to the first supply manifold for the heat exchange tubes. The first tube circuit exits into a return manifold at $1100^{\circ} \mathrm{C}$. The second tube circuit is fed at $800^{\circ} \mathrm{C}$ and exits at $1100^{\circ} \mathrm{C}$.

One of the primary goals of the APEX study is to increase the availability of fusion reactors by increasing the mean time between failures and by decreasing the mean time to repair. To this end, we recommended the approach of sector maintenance, modular maintenance for everything and pre-tested modules for all components. 


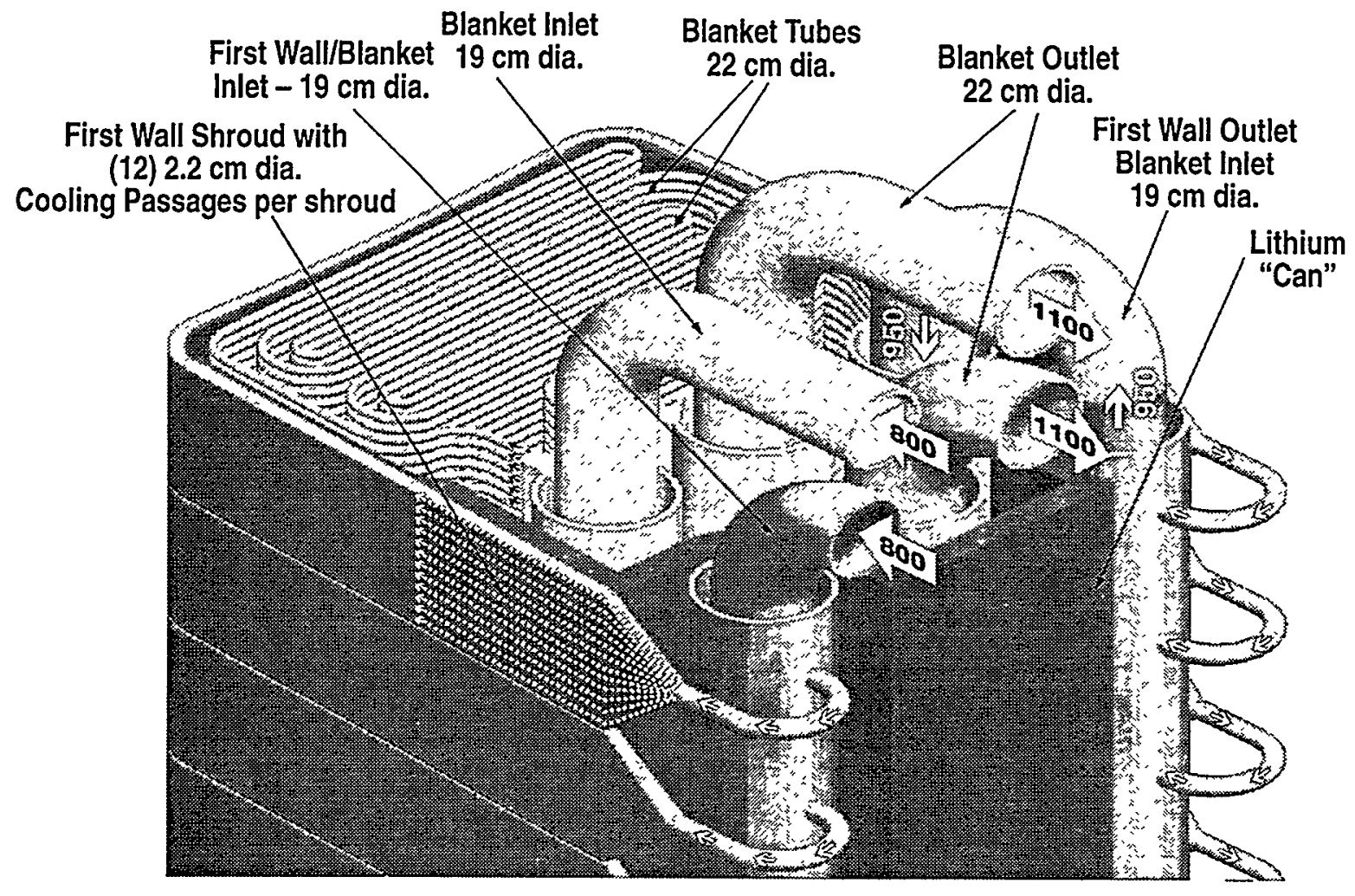

Fig. 1. Helium cooled first wall and divertor design module. 


\section{FIRST WALL BLANKET THERMAL-HYDRAULICS DESIGN AND ANALYSIS}

\subsection{DESIGN INPUTS}

With the mechanical design concept described in Section 3, we determined the material volume fractions and power generation from different FW/blanket zones. We performed iterative calculations between thermal hydraulics and nuclear analysis. The normalized volumetric power density for $\mathrm{W}$-alloy as a function of distance $\mathrm{x}$ from the first wall is approximated by $\mathrm{PW}(\mathrm{x})=$ $9 \mathrm{e}^{-3 \mathrm{x}}$ w/cc per neutron wall loading in $\mathrm{MW} / \mathrm{m}^{2}$. The normalized volumetric power density for Li-breeder is approximated by $\operatorname{PLi}(x)=4 e^{-3 x} w / c c$. Other input parameters are:

$\begin{array}{ll}\text { Reactor power output } & 2005 \mathrm{MWe} \\ \text { Helium pressure } & 12 \mathrm{MPa} \\ \text { Helium mass flow-rate } & 2528 \mathrm{~kg} / \mathrm{s} \\ \text { Helium } \mathrm{T}_{\text {in }} / \mathrm{T}_{\text {out }} & 800^{\circ} \mathrm{C} / 1100^{\circ} \mathrm{C} \\ \text { Structural material } & \mathrm{W}-5 \mathrm{Re} \\ \text { Max. neutron wall loading } & 7.49 \mathrm{MW} / \mathrm{m}^{2} \\ \text { Max. surface heat flux } & 2.16 \mathrm{MW} / \mathrm{m}^{2}\end{array}$

\subsection{FIRST WALL DESIGN}

The use of helium as a FW/blanket, divertor coolant has been proposed in various fusion design studies. For example, helium cooling was selected for the ARIES-I tokamak reactor design [2]. Analysis of the effectiveness of heat transfer enhancers such as surface roughening and fins was done for helium-cooled divertor options for ITER [3], and a further review of heat transfer enhancement was performed by Baxi [4]. To handle the high surface heat load, extended heat transfer enhancements by porous medium and swirl tape were evaluated. 


\subsubsection{Porous Medium}

A porous medium enhances heat transfer from the wall to the helium thereby reducing the film temperature drop and the absolute temperatures of the first wall. The design activity reported here was based in part upon development activities by two small U.S. businesses. One of the companies, Thermacore, Inc. uses a porous medium to enhance heat transfer. Thermacore designed and built a series of helium-cooled modules that were tested at Sandia and elsewhere [5-7]. One advance in their development of a helium-cooled heat sink was the development of designs that connected open axial inlet and exhaust passages to circumferential flow passages that contained the porous medium, as shown in Fig. 2. The other company, Ultramet, Inc. has experience in fabrication of refractory materials. Ultramet has designed and built commercial products made of refractory metals for rocket nozzles and other applications in which they use a metallized foam that is integrally bonded to fully dense material [8], as shown in Fig. 3. Their experience demonstrates that a tungsten channel with integrated porous medium structure can be fabricated.

To minimize the thermal stress, thermal analysis of 2-D models was done on a double tube wall design for a surface heat load of $2 \mathrm{MW} / \mathrm{m}^{2}$ and an internal pressure of $10 \mathrm{MPa}$. At $1000^{\circ} \mathrm{C}$, the maximum von Mises stress is $80 \mathrm{MPa}$ which is much lower than the allowable total stress

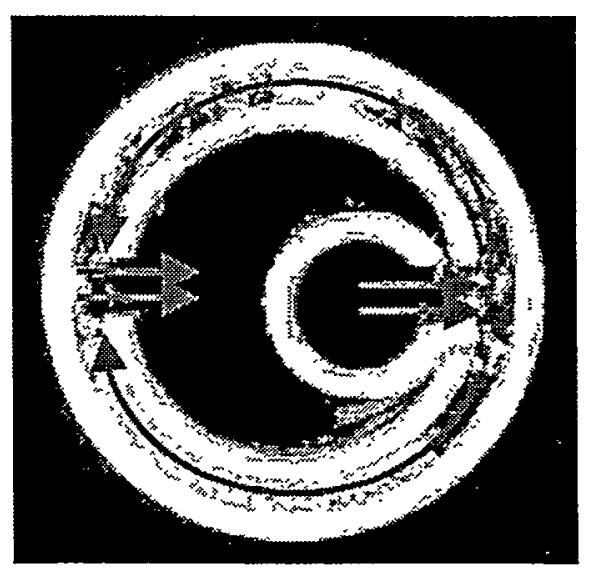

Fig. 2. Thermacore circumferential flow design porous Ta implant. 


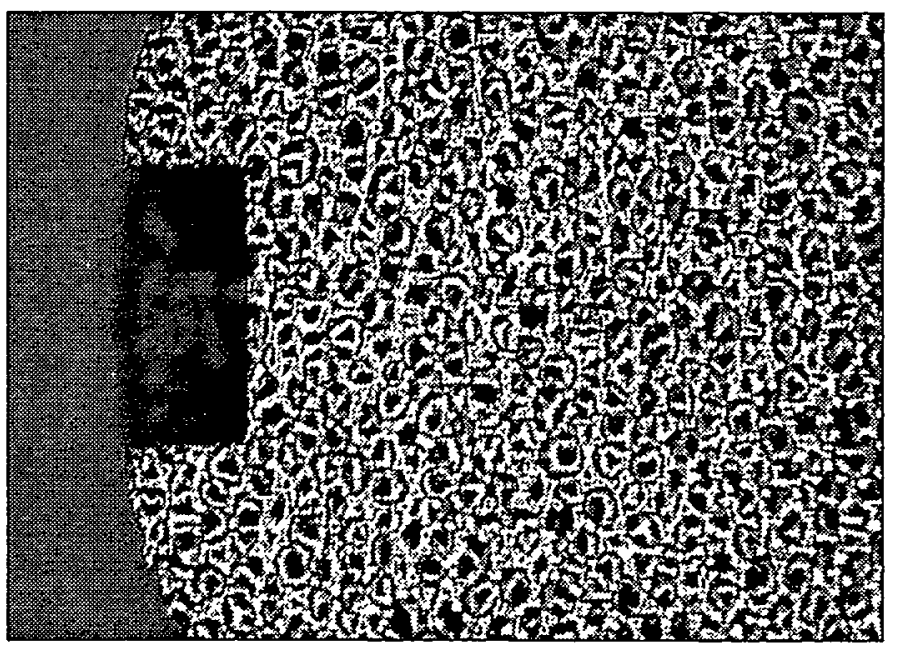

Fig. 3. Porous Ta implant, diameter $=0.75$ in .

(primary+secondary) of $228 \mathrm{MPa}=$ ultimate stress. Further iteration will be needed for the reference case of $12 \mathrm{MPa}$ pressure but the result should not be significantly different. The double tube wall design will then be incorporated into the porous medium design in the next design phase.

\subsubsection{Swirl Tape First Wall Design}

Another method for extended surface heat transfer is to use a swirl tape insert. Swirl tape increases the heat transfer coefficient by increasing the effective flow velocity of the coolant and increasing mixing. There is a large amount of reliable data available on this method. However, the corresponding increase of coolant flow friction factor has to be accounted for.

For this calculation the enhancement in heat transfer coefficient is given by, $h_{e n}=2.18 / Y^{0.09}$, and the increase in friction factor is given by $\mathrm{f}_{\mathrm{en}}=2.2 / \mathrm{Y}^{0.406}$, where $\mathrm{Y}$ is the twist ratio defined by pitch $/ 2 *$ diameter of the tube. Therefore the equivalent $h_{\mathrm{eq}}=\mathrm{h}_{\mathrm{en}} * \mathrm{~h}$ and equivalent friction fractor $f_{e q}=f_{e n} * f$, where $h$ and $f$ are heat transfer coefficient and friction factor for a simple circular tube, respectively. In the following calculation we used $Y=2$. 
Using a maximum neutron wall loading of $7.11 \mathrm{MW} / \mathrm{m}^{2}$, and maximum surface heat flux of $2.06 \mathrm{MW} / \mathrm{m}^{2}$, and the swirl-tube first wall coolant velocity range of 54 to $62 \mathrm{~m} / \mathrm{s}$, the W-alloy maximum temperature was found to be in the range of $1073^{\circ} \mathrm{C}$ to $1242^{\circ} \mathrm{C}$. With simple tubes in the blanket, the $\mathrm{W}$-alloy maximum temperature is $1199^{\circ} \mathrm{C}$, and the lithium maximum temperature is $1228^{\circ} \mathrm{C}$.

The first wall and blanket system pressure drop was also estimated. Including frictional losses, turns, contractions, expansions, and main helium inlet and outlet pipes, the total pressure drop was estimated to be $0.61 \mathrm{MPa}$, which gives a $\triangle \mathrm{P} / \mathrm{P}$ of $5.1 \%$.

\subsection{THERMAL STRESS ANALYSIS OF APEX FIRST WALL DESIGN}

A "ground rule" of the APEX study was that structures should be robust, and specifically, $3 \mathrm{~mm}$ was taken as a nominal first wall thickness. A central challenge in the design is to relieve the primary and secondary stresses that results from the high helium pressure, surface heat load and the related steep thermal gradient in the heated surface. The FW is permitted to flex to relieve the thermal strain (bending stresses) form the surface heat load.

A thermal analysis of a dual channel FW structure (without the porous medium included) was performed using 2-D plane strain models (PATRAN/ABAQUS) for a surface heat load of $2 \mathrm{MW} / \mathrm{m}^{2}$ and an internal pressure of $10 \mathrm{MPa}$; the FW was permitted to flex under the heat load. At $1000^{\circ} \mathrm{C}$, the maximum von Mises stress is $80 \mathrm{MPa}$, this is well within the suggested stress limits stated below. Further iteration will be needed for the reference case of $12 \mathrm{MPa}$ pressure but the result should not be significantly different. The double tube wall design will then be incorporated into the porous medium design in the next design phase.

The thermal stress due to a prescribed temperature distribution along a single tube first wall of the APEX FE/blanket was also analyzed using the COSMOS finite element code. The structural model consisted of 2-D beam elements interconnected along with the defined temperature distribution. The first wall tube has an ID of $1.6 \mathrm{~cm}$ and an $\mathrm{OD}$ of $2.2 \mathrm{~cm}$. The beam 
elements representing the lithium case are $0.2 \times 2.2 \mathrm{~cm}$ for the inner case and $3.8 \times 2.2 \mathrm{~cm}$ for the outer strong back case. The lithium case is supported by a guide structure attached to the vacuum vessel. It is assumed that the guide structure allows free thermal expansion of the lithium case in the vertical and radial directions. The following W-5Re alloy properties were taken at $1000^{\circ} \mathrm{C}$ :

Young's modulus $=392 \mathrm{GPa}$

Poisson's ratio $=0.267$

Coefficient of thermal expansion $=3.96 \times 10^{-6} /{ }^{\circ} \mathrm{C}$

The deformed shape and maximum stress due to the prescribed assigned temperature distribution and boundary conditions were calculated. The tangential thermal growth of the first wall tube of $2.0 \mathrm{~mm}$ requires that the blanket modules be installed with $4.0 \mathrm{~mm}$ gaps in the cold condition to prevent contact with one another during operation. The radial thermal growth of the plasma facing tube is $4.4 \mathrm{~mm}$.

Since we projected that the irradiated W-alloy should be treated more as a brittle than ductile structural material, we proposed that the stress criteria for evaluating calculated stress intensities for tungsten materials be taken as $1 / 2$ the ultimate stress $(133 \mathrm{MPa})$ at $1000^{\circ} \mathrm{C}$ for welded joints and 2/3 the ultimate stress (177 MPa) away from joints. Adopting these criteria, the allowable stress at the weld joint due to all load combinations is $152 \mathrm{MPa}$ at $1000^{\circ} \mathrm{C}$.

Since the proposed support structure will allow free thermal expansion of the lithium case, only the temperature difference between the first wall tube and lithium case will induce thermal stresses. The maximum thermal stress occurs in the first wall tube at its junction to the lithium case and is only $6 \mathrm{MPa}$. 
Although the proposed concept for supporting the blanket induces low thermal stress, details of how to implement the support concept will certainly result in higher thermal stresses. Also, the stresses due to dead weight, pressure, and disruption loads have yet to be calculated. This will be performed in the next phase of design. 


\section{NUCLEAR ANALYSIS}

Based on the material volume fractions generated, we iterated with the thermal hydraulics task and assessed the impact of W-alloy on the nuclear heating profiles across the blanket and power multiplication (PM), and on the tritium breeding profiles and the tritium breeding ratio (TBR). The impact of Li-6 enrichment on these profiles and on TBR and PM is also assessed. In addition, we assessed the damage indices, expressed in terms of DPA, helium, and hydrogen production rates at several key locations, including the vacuum vessel (V.V.) and TF coil case. When compared to other refractory alloys like TZM and $\mathrm{Nb}-1 \mathrm{Zr}$, the best local TBR performance is with $\mathrm{W}$ and $\mathrm{Li}$ breeder. The TBR increases with $\mathrm{Li}-6$ enrichment and starts to saturate at a value of $\sim 1.43$ when $\mathrm{Li}-6$ enrichment is $\sim 35 \%$.

The damage parameters, dpa rate, helium and hydrogen production rate at various locations were estimated in the $\mathrm{W}$-alloy design. Compared to the liquid breeder Flibe, liquid lithium is the less effective material in attenuating the nuclear flux at the V.V. and TF coil by a factor of 6 to 10.

The radioactive waste characteristics of the different components of the machine were evaluated according to both the NRC 10CFR61 [9] and Fetter waste disposal concentration limits (WDR) [10]. According to Fetter limits, the first wall, module wall, blanket, and transitional zone would not qualify for disposal as Class $\mathrm{C}$ waste. As a matter of fact the W-5Re alloy produces such a high activity that the first wall would have a WDR which is more than order of magnitude higher than the Class C WDR limits. The high WDR is due to the $186 \mathrm{~m} R e, 108 \mathrm{~m} A g$, and ${ }^{94} \mathrm{Nb}$ isotopes. Only $186 \mathrm{mRe}$ is a product of nuclear interactions with base elements in the W$5 \operatorname{Re}$ alloy. 


\section{POWER CONVERSION SYSTEM}

The major incentive for employing high-temperature refractory alloy FW/blanket with helium cooling in this design is to enable direct coupling with a CCGT (Brayton Cycle) for high efficiency power conversion. This has the advantage of eliminating an intermediate hightemperature $\mathrm{He} / \mathrm{He}$ heat exchanger (HX), which would be a significant technical challenge. However, the potential for tritium contamination in the power conversion system (PCS) must be addressed, and appropriate design measures must be taken to prevent further spread of contamination and to facilitate maintenance of PCS components. Figure 4 shows the effect of FW/blanket inlet temperature variation on PCS performance for the selected outlet temperature of $1100^{\circ} \mathrm{C}$. Based on this the selected gross efficiency for the preliminary design is $57.5 \%$.

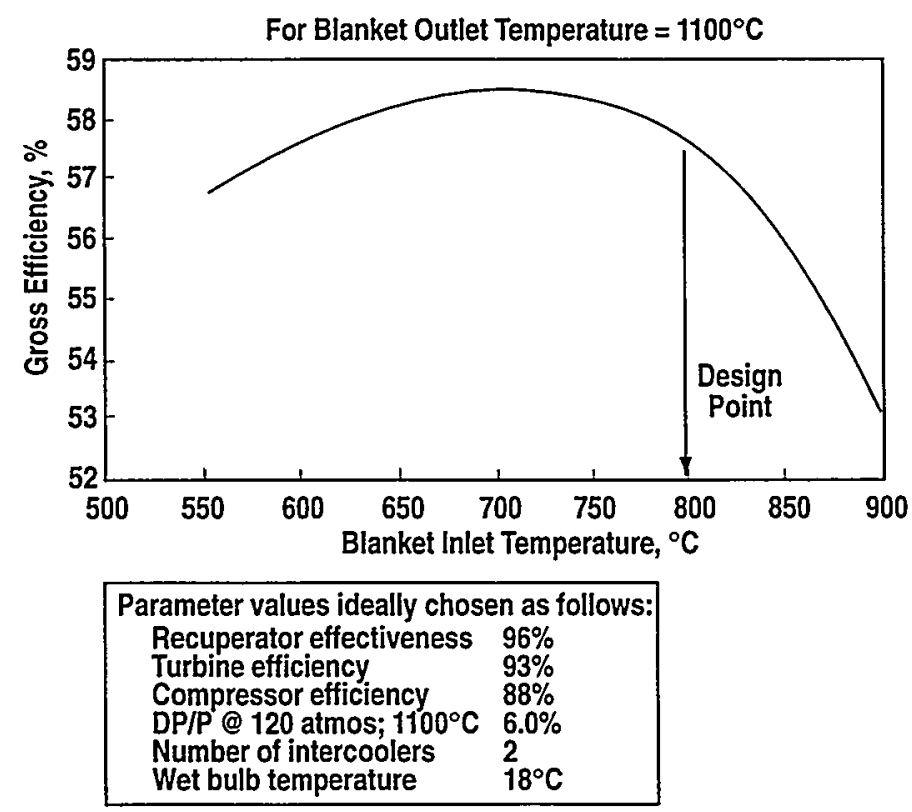

Fig. 4. Effect of FW/blanket inlet temperature on power conversion system gross efficiency. 


\section{TRITIUM MIGRATION AND CONTROL}

Ttitium produced in the lithium has to be recovered with an acceptable tritium inventory. The design goal of the tritium recovery system for lithium is usually to limit the tritium concentration to about $1 \mathrm{appm}$. This goal is to limit the total tritium inventory in the lithium to less than $200 \mathrm{~g}$. The $200 \mathrm{~g}$ tritium inventory in one unit in the fusion power plant is the safety limit selected for the ITER design.

Many processes have been proposed to recover tritium from lithium. A recent proposal is to recover tritium using the cold trap process [11]. This process has been demonstrated to recover tritium from lithium to the saturation concentration [12]. However, the saturation tritium concentration at $200^{\circ} \mathrm{C}$ is about $250 \mathrm{appm}$, far exceeding the design goal of $1 \mathrm{appm}$. The new proposal is to add protium to the lithium. With the total hydrogen concentration at the saturation limit of 250 appm, the tritium concentration can be below $1 \mathrm{appm}$. The design of the process and the cost associated with the separation of $\mathrm{T}$ from $\mathrm{H}$ was calculated for ITER [13] and was judged to be acceptable.

The lithium flow rate for tritium recovery is $20 \mathrm{~kg} / \mathrm{s}$. This is a very small flow rate. To maintain uniform tritium concentration, the local flow rate has to be controlled. The tube bank configuration of the preliminary design is amenable to radial segmentation, but the detailed design of lithium flow control from all regions inside the blanket will still be a challenge. If the lithium flow rate is non-uniform, certain local tritium concentrations will be high, and higher tritium inventory can be expected. This design impact will have to be assessed.

Tritium will permeate to the He coolant both by pressure driven from the blanket and by plasma driven permeation across the first wall, so a tritium clean up system will be required. Recent experimental results from Tritium System Test Assembly (TSTA) [14] shows that a permeation window can be used for tritium cleanup from a gas. This process is capable of removing tritium from a gas to $\sim 1 \mathrm{~Pa}$. Since permeation is not a critical issue for this design, $1 \mathrm{~Pa}$ tritium partial pressure may be acceptable. The effect of this tritium partial pressure on the 
operation of the pumps and valves will have to be assessed. As presented in the last section, the problem of PCS contamination will have to be addressed also. 


\section{SAFETY}

\subsection{DECAY HEAT REMOVAL}

The use of tungsten as the structural material in this concept poses some safety challenges. Tungsten is a radiologically hazardous material with high decayheat, so we must ensure that the design is such that long-term accident temperatures are low enough that unacceptably large amounts of tungsten are not mobilized during an accident. Our preliminary calculations show that design options exist that result in long-term temperatures below $800^{\circ} \mathrm{C}$. Details can be found in McCarthy et al. [15].

\subsection{OTHER SAFETY ISSUES AND RELIABILITY ISSUES}

Because liquid lithium is present in this design to provide tritium breeding, safety design necessary for the use of lithium in a power producing system will have to be followed. As more design details become available, further safety analyses will be done to ensure that safety requirements are met. Similarly, a reliability assessment will need to be done when more design details are available. 


\section{SYSTEM DESIGN}

With the potential of the high performance helium-cooled W-alloy FW/blanket design, the economics of a tokamak reactor was assessed by utilizing the GA-system code [16]. Physics parameters were based on the results from plasma equilibrium calculations. This code uses ARIES-RS [17] and ARIES-ST [18] as reference design points, and the performance and cost of electricity $(\mathrm{COE})$ of superconducting and normal conducting coil reactors could be projected for difference aspect ratio, power output and neutron wall loading designs [16]. Based on the projected gross thermal efficiency of $57.5 \%$, the maximum neutron wall loading only needs to be operated at $7.2 \mathrm{MW} / \mathrm{m}^{2}$, with a corresponding maximum first wall heat flux of $2.07 \mathrm{MW} / \mathrm{m}^{2}$. In summary, at the thermal efficiency of 57.5\%, a superconducting reactor with an aspect ratio of 4 and an output power of $2 \mathrm{GWe}$ is projected to have a COE of $54.66 \mathrm{mill} / \mathrm{kWh}$. 


\section{KEY ISSUES AND R\&D}

We have completed the preliminary design of a helium-cooled refractory alloy FW/blanket design. Many development issues are identified in different areas of the design. The following is a list of key issues, grouped by areas, which will have to be addressed in order to become a viable design.

Materials: $\quad$ Irradiated and engineering design material properties of W-alloy

Design criteria for W-alloy

Fabrication of W-alloy components

Minimum cost of fabricating W-alloy components

Compatibility between helium impurities and W-alloy

Design: Coolant routing

Structural support

High temperature piping

Develop robust high performance components

Thermal hydraulics: Helium flow control, distribution and stability

FW/Blanket temperature management and startup

Removal of afterheat during LOCA

Plasma interaction: W-surface compatibility with high performance plasma

Tritium: $\quad$ Extraction, inventory and PCS contamination

In addition, the availability of fusion power core components will have to be demonstrated. 


\section{CONCLUSIONS}

We completed the preliminary design of a high performance He-cooled W-5Re alloy FW/blanket design. A separate first wall that is permitted to flex under heating and a lithium pool configuration was selected. Due to the lack of irradiated data, conservative assumptions on selecting the W-alloy properties have to be used. With regard to the compatibility of W-alloys with oxygen as the primary helium impurity, commercially available solid gettering modules can maintain the impurity level to $<1$ appm and prevent embrittlement. Potentially, based on the results of selected analyses, the FW/blanket design could meet the material temperature and structural design limits, provided that the peak structural loading during disruptions can be mitigated. The 1-D tritium breeding ratio of 1.43 can be reached with a $\mathrm{Li}-6$ enrichment of $35 \%$. But the presence of induced radioactivity will not allow the W-alloy components to meet the criteria for classification as low level waste. W-alloy will generate a high level of afterheat, but, with the tritium extraction system operating, long-term accident temperatures remain below $800^{\circ} \mathrm{C}$. A cold trap process with added protium to the lithium could be used for tritium extraction. At the CCGT gross thermal efficiency of $57.5 \%$, a superconducting reactor with an aspect ratio of 4 and an output power of $2 \mathrm{GWe}$ is projected to have a COE of $54.66 \mathrm{mill} / \mathrm{kWh}$. Critical issues were identified and we plan to continue the evaluation on some of the critical issues during the next phase of the APEX design study. 


\section{REFERENCES}

[1] M. Abdou et al., "The APEX program", Int. Symp. on Fusion Technology, Rome, September 1999, to be published.

[2] F. Najmabadi et al., "The ARIES-I Tokamak Reactor Study, Final Report" UCLA-PPG$1323,1991$.

[3] M.S. Tillack et al., "Helium-Cooled Divertor for ITER: A Study of Cooling Options, Requirements and Limits," ITER Report published by UCLA as "UCLA-FNT-67 UCLAENG-93-22, April 1993.

[4] C. Baxi and C. Wong, "Review of Helium Cooling for Fusion Reactor Applications," Int. Symp. on Fusion Technology, Rome, September 1999, to be published.

[5] M.T. North and J.H. Rosenfeld, "Test Results from a Helium Gas-cooled Porous Metal Heat Exchanger," High Heat Flux Engineering III, ed. Khonsary, Vol. 2855 (1996), ISBN 0-8194-2243-6.

[6] D.L. Youchison and J.M. McDonald, "Thermal Performance and Flow Instabilities in a Multi-channel, Helium-cooled, Porous Metal Divertor Module," Int. Symp. on Fusion Technology, Rome, September 1999, to be published.

[7] D.L. Youchison, M.G. Izenson, C.B. Baxi, J.H. Rosenfeld, "High Heat Flux Testing of Helium-Cooled Heat Exchangers for Fusion Applications," Fusion Technology Vol. 29 (no.4) July 1996, p.559-570.

[8] H. Kurishita et al., "Effect of Neuton-Irradiation on Low temperature Toughness of TiCdispersed Molybdenum Alloys," J. Nucl. Mat., 239(\#1-3) p253 (1996).

[9] Nuclear Regulatory Commission, 10CFR part 61, "Licensing Requirements for Land Disposal of Radioactive Waste," Federal Register, FR 47, 57446 (1982).

[10] S. Fetter, E. Cheng and F. Mann, "Long Term Radioactive Waste from Fusion Reactors," Fusion Engineering and Design 13, 239-246 (1990). 
[11] D.K. Sze, R.F. Mattas, J. Anderson, R. Haange, H. Yoshida, and O. Kveton, Tritium Recovery based on Cold Trap,ISFNT-3, Los Angles, Ca. June, 1994.

[12] E. Veleckis and V.A. Maroni, "Thermodynamic Proporties of Solutions in Hydrogen Isotopes in Metals and Laooys of Interest to Fusion Reactor Technology," Proc. of Int. Conf. on Rdaition Effects and Tritium Technology for Fusion Reactors, Gatlingburg, Tn. October 1975.

[13] D.K. Sze, R.F. Mattas, J. Anderson, R. Haange, H. Yoshida, and O. Kveton, "Tritium Recovery from Lithium Baded on Cold Trap," ISFNT-3, Los Angeles, California, (1994).

[14] S. Willms, LANL, private communication.

[15] McCarthy, et al., "Safety Issues Due to Mobilized Activation Products in Selected APEX Designs," Int. Symp. on Fusion Technology, Rome, September 1999, to be published.

[16] C.P.C. Wong, R.D. Stambaugh, "Tokamak Reactor Designs as a Function of Aspect Ratio," Int. Symp. on Fusion Technology, Rome, September 1999, to be published.

[17] M.S. Tillack, "ARIES-RS Tokamak Power Plant Design," Special Issue, Fusion Engineering and Design, 38, 1-218, 1997.

[18] R.L. Miller "Design Point Determination for the Commercial Spherical Tokamak, ARIES-ST," Proc. of the 17 IEEE Symposium on Fusion Engineering, p. 1031, (1997). 


\section{ACKNOWLEDGMENT}

Work supported by the U.S. Department of Energy under Contracts DE-AC03-98ER54411, DE-AC04-94AL85000, DE-AC05-96OR22464, W-31-109-ENG-38, W-7405-ENG-36, and Grant No. DE-FG03-86ER54299. 